\title{
Resposta paradoxal durante o tratamento para tuberculose manifestada como tuberculoma do sistema nervoso central
}

Paradoxical response during antituberculosis therapy for manifested

like tuberculoma of the central nervous system

Fábio Lopes Pedro ${ }^{1}$, Fábio Pascotto de Oliveira ${ }^{2}$, Helen Minussi Cezimbra ${ }^{3}$, Sarita Quatrin
Buzzeto Santos ${ }^{4}$, Fernanda Paula Franchini ${ }^{5}$, Lucas de Figueiredo Rosa ${ }^{6}$, Helena Noal

${ }^{1}$ Professor do curso de medicina (UFSM), Mestre em epidemiologia (UFRGS), Coordenador do Núcleo de Vigilância Epidemiológica (HUSM)

${ }^{2}$ Médico Neurologista (HUSM)

3,4 Médica Residente em Infectologia (HUSM)

${ }_{5}^{5}$ Médica Residente em Clínica Médica (HUSM)

${ }^{6}$ Médico (UFSM)

${ }^{7}$ Enfermeira coordenadora do Núcleo de Vigilância Epidemiológica

Hospitalar (HUSM), Santa Maria - RS - Brasil

fabiopedro@gmail.com

Paciente masculino, 31 anos, pardo, ex-presidiário, ex-usuário de drogas, homossexual, natural e procedente do interior do Rio Grande do Sul (RS), foi admitido no Hospital Universitário de Santa Maria (HUSM) por dispnéia progressiva e dor torácica ventilatório-dependente bilateral. Apresentava tosse seca, sudorese noturna, calafrios, perda ponderal de $10 \mathrm{~kg}$, adinamia e anorexia há dois meses. Ao exame físico, apresentava-se em regular estado geral, com pupilas isocóricas e fotorreagentes, sem alterações neurológicas, febril (temperatura axilar de $38,4^{\circ} \mathrm{C}$ ), hipotenso (pressão arterial de $85 \times 49 \mathrm{mmHg}$ ) e taquicárdico (frequência cardíaca de 140 bpm). Radiografia de tórax evidenciou infiltrado micronodular difuso com consolidação no lobo superior direito. Lavado broncoalveolar foi positivo para bacilos álcool-ácido resistente (BAAR). Anti-HIV1/2, anti-HCV, VDRL, HBsAg, HTLV1/2 foram negativos. Diante do diagnóstico de tuberculose, foi iniciado tratamento em dose máxima para adultos com rifampicina, isoniazida, pirazinamida e etambutol (RHZE). O paciente teve boa evolução, com remissão dos sintomas em sete dias, sendo liberado para trata- mento ambulatorial.

Um mês após início do tratamento foi readmitido, apresentando plegia de membro inferior direito, parestesia de membro superior direito e inferior esquerdo, acompanhadas de incontinência urinária e fecal, com um dia de evolução. Ao exame físico apresentava-se orientado, com pupilas isocóricas e fotorreagentes; movimentos oculares preservados, sem alterações de pares cranianos; reflexos dos membros superiores normais, porém diminuídos nos inferiores; sensibilidade térmica e dolorosa preservadas; sinal de Babinski ausente. Ressonância nuclear magnética de encéfalo e de coluna cervical demonstrou múltiplas e extensas áreas de hiperssinal T2, predominando em substância branca subcortical de ambos os hemisférios cerebrais, na porção direita do tronco cerebral e em hemisférios cerebelares, principalmente à direita. Em meio a essas alterações, evidenciou-se realce nodular de lesões menores que um centímetro, sugestivas de infecção oportunista (Figura 1A e B). Medula cervical com extensa área de hiperssinal em T2, com realce pelo contraste, medindo cerca de um centímetro no seu maior eixo, provavelmen- 
te de mesma etiologia que as alterações descritas no encéfalo (Figura 2). Hipóteses diagnósticas de tuberculoma, meningite tuberculosa, metástases e abscessos foram aventadas. Punção lombar evidenciou líquor pouco turvo, com contagem de leucócitos normal e raras hemácias, hipoglicorraquia. Exame bacterioscópico, pesquisa de BAAR, e culturas foram negativas. Ecocardiograma transesofágico foi normal. Biópsia estereotáxica das lesões não foi realizada devido à indisponibilidade da técnica nessa instituição. PCR DNA para $M$. tuberculosis no líquor foi negativo.

Considerando a impossibilidade de investigação etiológica por exame cultural ou anatomo-patológico das lesões cerebrais, e em tendo em vista quadro de tuberculose pulmonar, optou-se por iniciar dexametasona $12 \mathrm{mg}$ por dia, intravenosa, por um mês. Após o término do curso de dexametasona, iniciou-se prednisona $60 \mathrm{mg}$ por dia, via oral, com redução progressiva da dose. O tratamento com RHZE foi mantido. Paciente apresentou melhora significativa da plegia, parestesia e incontinência fecal após 20 dias do início do corticosteróide, porém permaneceu com incontinência urinária. Tomografia computadorizada de crânio realizada após dois meses do quadro não evidenciou quaisquer alterações.

A reação paradoxal é conhecida como uma piora clínica ou radiológica de lesões tuberculosas pré-existentes ou como desenvolvimento de novas lesões em um paciente que, inicialmente, obteve melhora após início de antituberculosos ${ }^{1}$. Levando-se em consideração que ela não é um fenômeno raro $^{1}$, sendo identificada em $6 \%$ a $30 \%$ dos pacientes recebendo antituberculosos1, tanto em imunocompetentes como em imunodeprimidos ${ }^{2,3,4}$, e tratando-se de diagnóstico difícil, por ser de exclusão ${ }^{1}$, o conjunto de sinais, sintomas e evolução clínica do paciente nos conduziu ao diagnóstico de reação paradoxal após início de medicamentos antituberculose.
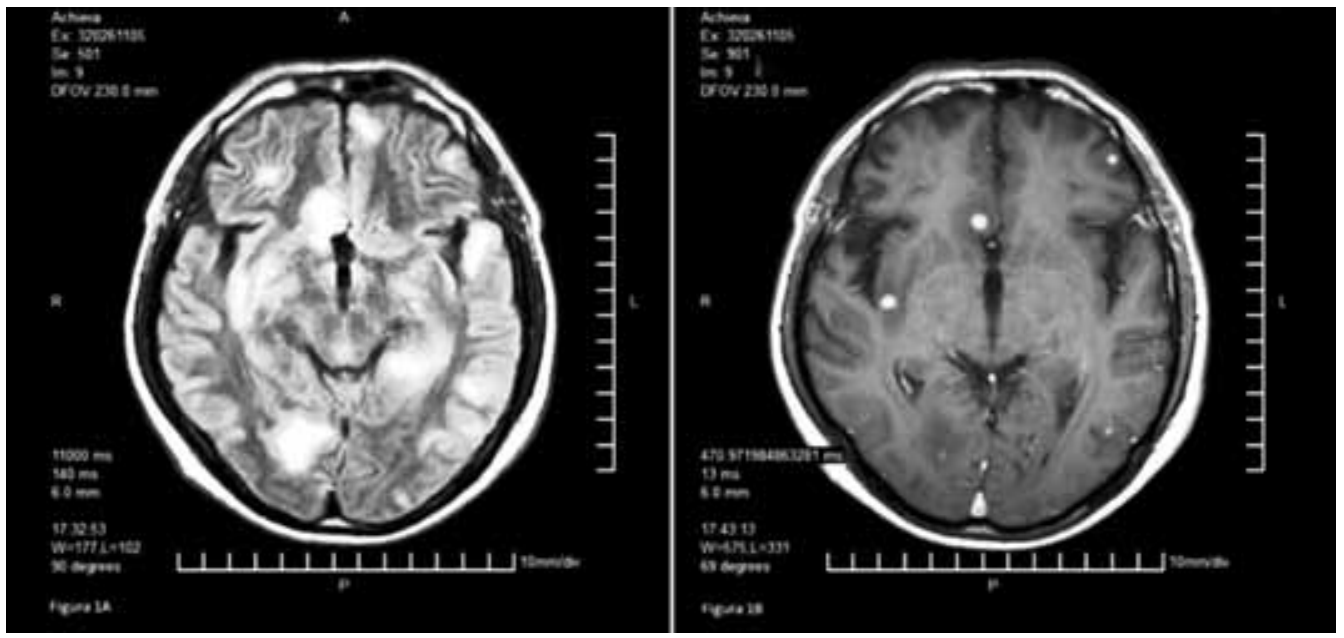

Figura 1A e 1B - A) Ressonância Nuclear Magnética demonstrando lesões nodulares difusas em Flair.

B) Ressonância Nuclear Magnética demonstrando lesões nodulares difusas, realçadas por contraste em T1. 


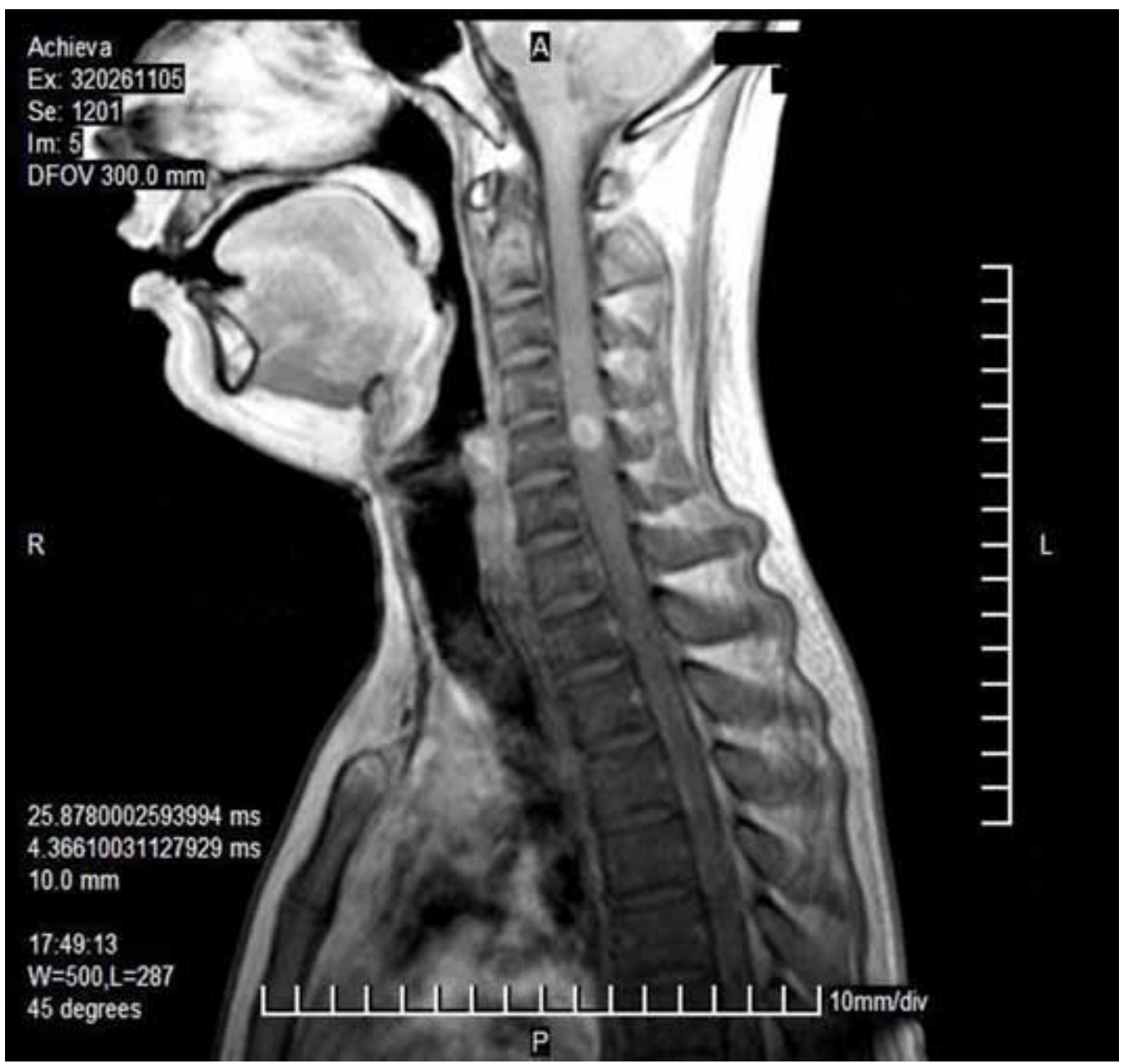

Figura 2 - Ressonância Nuclear Magnética da coluna cervical, demonstrando lesão única, realçada por contraste em T1.

\section{REFEFÊNCIAS}

1. Cheng VC, Ho PL, Lee RA, et al. Clinical spectrum of paradoxical deterioration during antituberculosis therapy in non-HIV-infected patients. Eur J Clin Microbiol Infect Dis 2002;21(11):803-809.

2. Al Majed SA. Study of paradoxical response to chemotherapy in tuberculous pleural effusion. Respir Med 1996;90(4):211-214.

3. Memish ZA, Mah MW, Mahmood SA, et al. Clinico-diagnostic experience with tuberculous lymphadenitis in Saudi Arabia. Clin Microbiol Infect 2000;6(3):137-141.

4. Breen RAM, Smith $\mathrm{CJ}$, Bettinson $\mathrm{H}$, et al. Paradoxical reactions during tuberculosis treatment in patients with and without HIV co-infection. Thorax 2004;59(8):704-707. 